Copyright (C) 2014 by Academic Publishing House Researcher

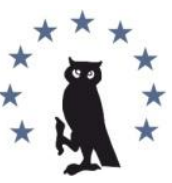

Published in the Russian Federation

European Researcher

Has been issued since 2010.

ISSN 2219-8229

E-ISSN 2224-0136

Vol. 84, No. 10-1, pp. 1736-1741, 2014

DOI: $10.13187 / \mathrm{er} .2014 .84 .1736$

www.erjournal.ru

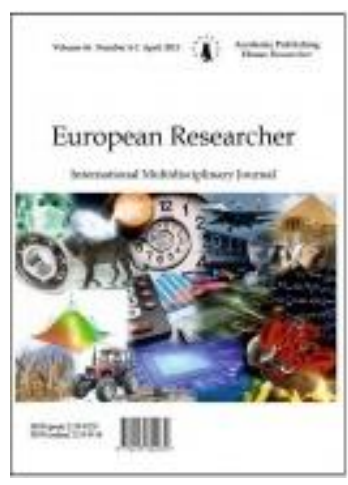

Historical sciences and archaeology

Исторические науки и археология

UDC 94(47).083

\title{
The "Matilda" Steamer - On the History of the First Experiments with Naval Aviation in Russia
}

\author{
${ }^{1}$ Roman V. Lapshin \\ ${ }^{2}$ Nicholas W. Mitiukov \\ 3 Vyacheslav I. Menkovsky
}

${ }^{1-2}$ International Network Center for Fundamental and Applied Research, Russian Federation

3 Belarusian State University, Belarus

Dr. (History), Professor

\begin{abstract}
This work examines the history of the "Matilda" steamer - the first ever ship in Russia capable of carrying airplanes. Although the results of the experiments did not become outstanding, they served as a point of departure for subsequent experiments with aviation in the Black Sea Fleet.

Keywords: Russia; naval aviation; hydro airplane; steamer.

Введение

Известно, что корабельная авиация российского флота получила свое развитие в годы Первой мировой войны. Для ее применения, в том числе и в интересах Черноморского флота, необходимы были суда, приспособленные под базирование гидросамолетов. В архивных документах и историографии отечественной морской авиации, охватывающих период Первой мировой войны, встречаются следующие термины: «авиационные суда», «авиатранспорты», «посыльные суда», «вспомогательные суда», «крейсера», «вспомогательные крейсера», «гидрокрейсера» [1]. Именно так именовались корабли (суда) русского военного флота, способные размещать на своих палубах гидроаэропланы и применять их в интересах флота. Однако первые эксперименты создания авиационных судов начались накануне Первой мировой войны. В статье нам бы хотелось уделить внимание одному из таких опытов на пароходе «Матильда».
\end{abstract}

\section{Материалы и методы}

В статье использовалась российская и зарубежная литература о первых опытах создания морской авиации в России [1-7]. Методологической основой статьи стали методы историзма, системности и объективности. Также нами был использован хронологический подход. 


\section{Результаты}

В 1894 г. по заказу норвежкой пароходной компании Jacob Christensen (Bergen) английская судостроительная компания "W. Gray \& Co., Ltd.» из West Hartlepool заложила под номером 497 однопалубный двухмачтовый товарный пароход со стальным корпусом «Mathilda». Водоизмещение - 9029 т, вместимость 3480 грт, длина полная 336 футов (102,15 м), длина по ватерлинии 325,5 футов (98,96 м), ширина 47,1 фут (14,26 м), осадка 7,3 фута (2,22 м), в полном грузу 24,8 футов (7,55 м). Одна вертикальная машина тройного расширения мощностью 9200 л.с. давала скорость 9,2 узла. На корабле стояло 4 котла, имелся 1 винт. Бортовые бункеры вмещали 341 т. угля, что при ходе 8 узлов обеспечивало дальность 3456 миль. Команда (в 1914 г.) - 26 чел. и 6 офицеров.

25 апреля 1895 г. корабль сошел на воду и в июне того же года отправился в первый рейс. Норвежскими хозяевами пароход использовался в основном как угольщик.

В январе 1904 г. «Mathilda» вышла с углем из Пенарта в Сасебо (Япония). Так как началась русско-японская война, 27 февраля ее задержал в Красном море миноносец «Бедовый» (из отряда адмирала Вирениуса) по подозрению в контрабанде. Угольщик привели в бухту Рас-Судр, но по приказу из Санкт-Петербурга 29 февраля пароход отпустили (к моменту задержания Россия еще не декларировала о контрабанде, поэтому задержание было незаконным).

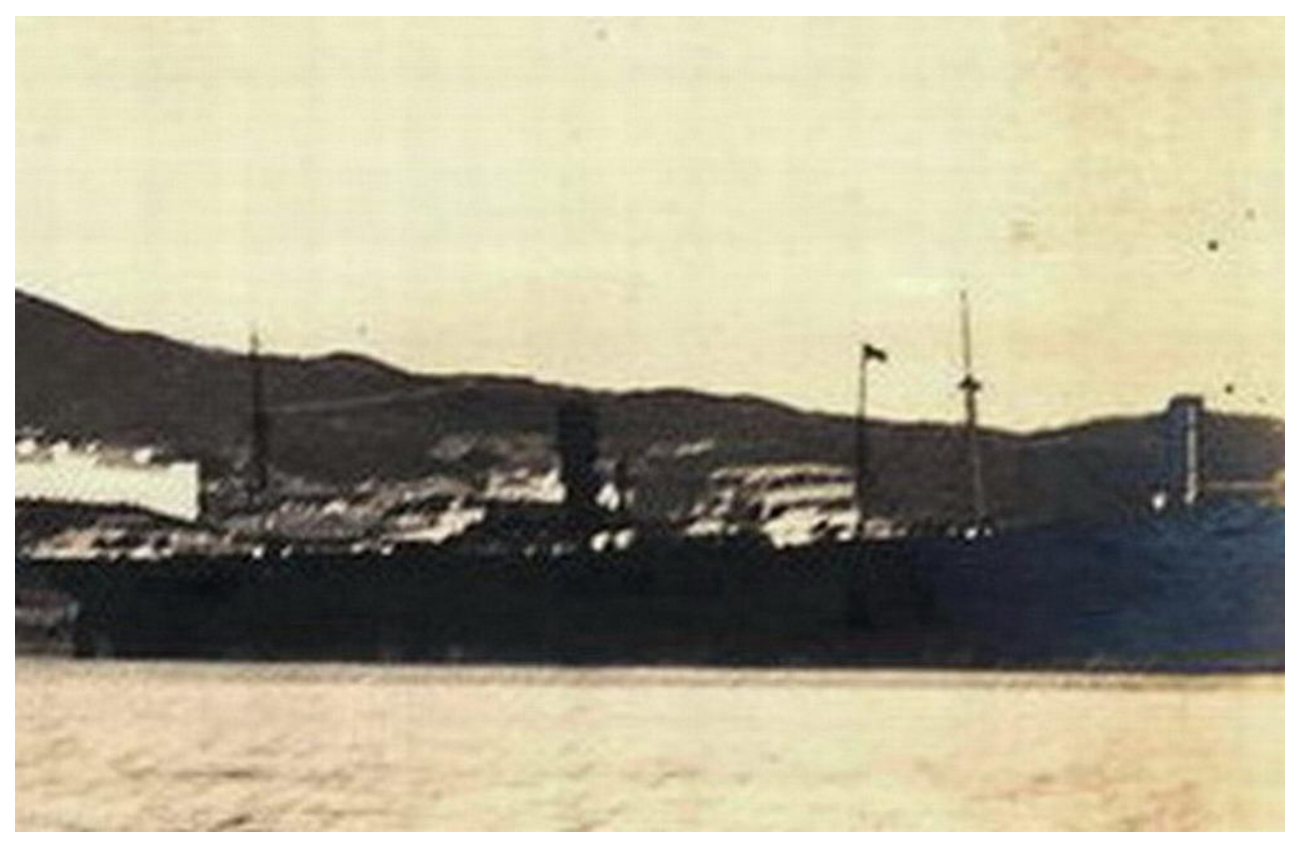

Фото 1. Вероятно, единственное сохранившееся фото "Матильды" во Владивостоке, 1904 г.

Но судно в итоге оказалось под русским контролем. 30 апреля 1905 г. когда оно находилось в Гонконге, «Матильду» купил за 312917 руб. посол в Корее Павлов по просьбе капитана 1 ранга Ливена (командира крейсера «Диана») для организации снабжения углем Второй эскадры Тихого океана. В результате пароход оказался под английским флагом (номер по регистру 120148, порт приписки Шанхай). В начале мая пароход прибыл в Шанхай, но необходимость в снабжении углем эскадру уже отпала. Отпала и необходимость в прикрытии английским флагом. Поэтому летом 1905 г. пароход поднял русский флаг и включен в регистры под названием «Матильда». 


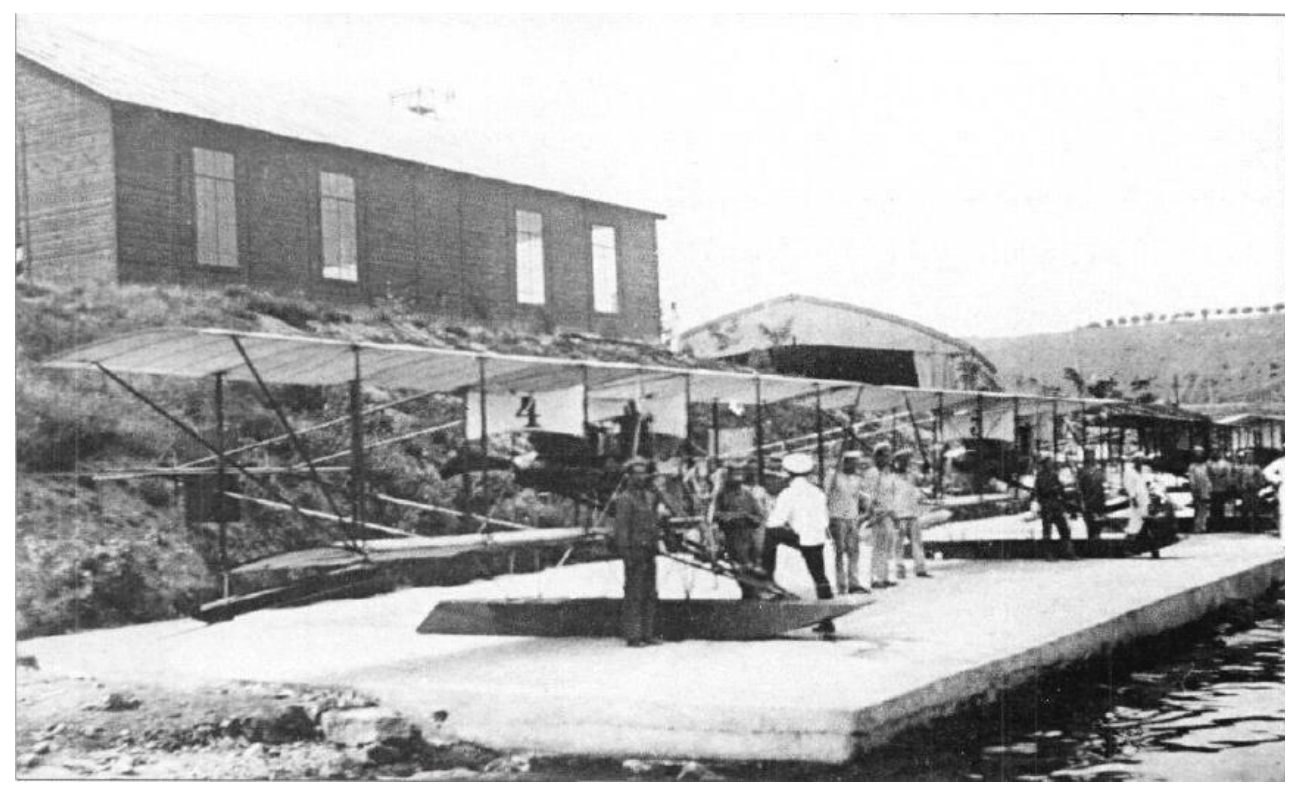

Фото 2. Аэроплан Кертиса тип D в Севастополе, 1913 г.

После войны пароход ушел во Владивосток, где его зачислили в Сибирскую флотилию как транспорт. С осени 1905 г. он перевозил русских пленных из Японии во Владивосток, затем - каботажные перевозки в Приморье.

15 июня 1906 г. сдан во фрахт пароходству «Русь», принадлежавшее графу Г.Г. Кейзерлингу и ушел из Владивостока на Чукотку. По окончании фрахта вернулся во Владивосток в августе 1906 г. и сдан в аренду лейтенанту Арсеньеву. В конце августа ушел на Черное море и вскоре стал в отстой. 1 мая 1909 г. зачислен в Черноморский флот как транспорт «Днепр».

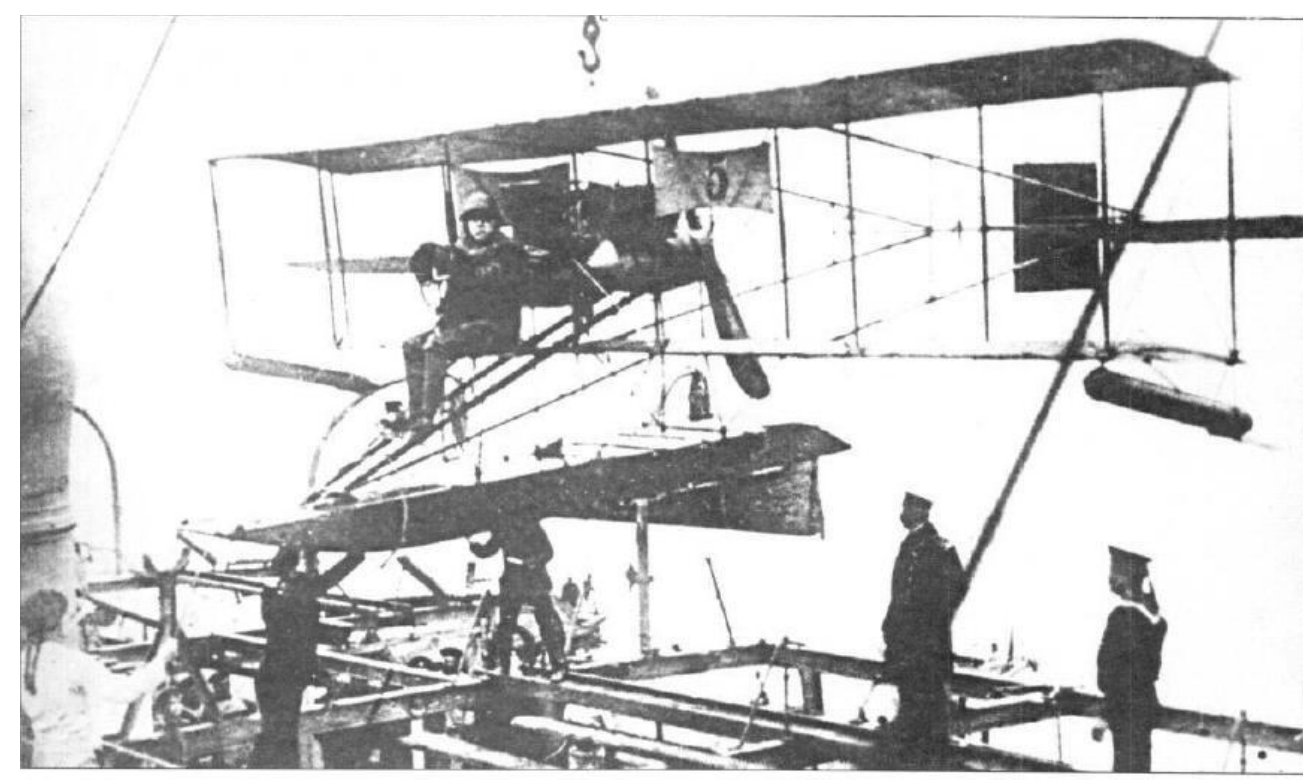




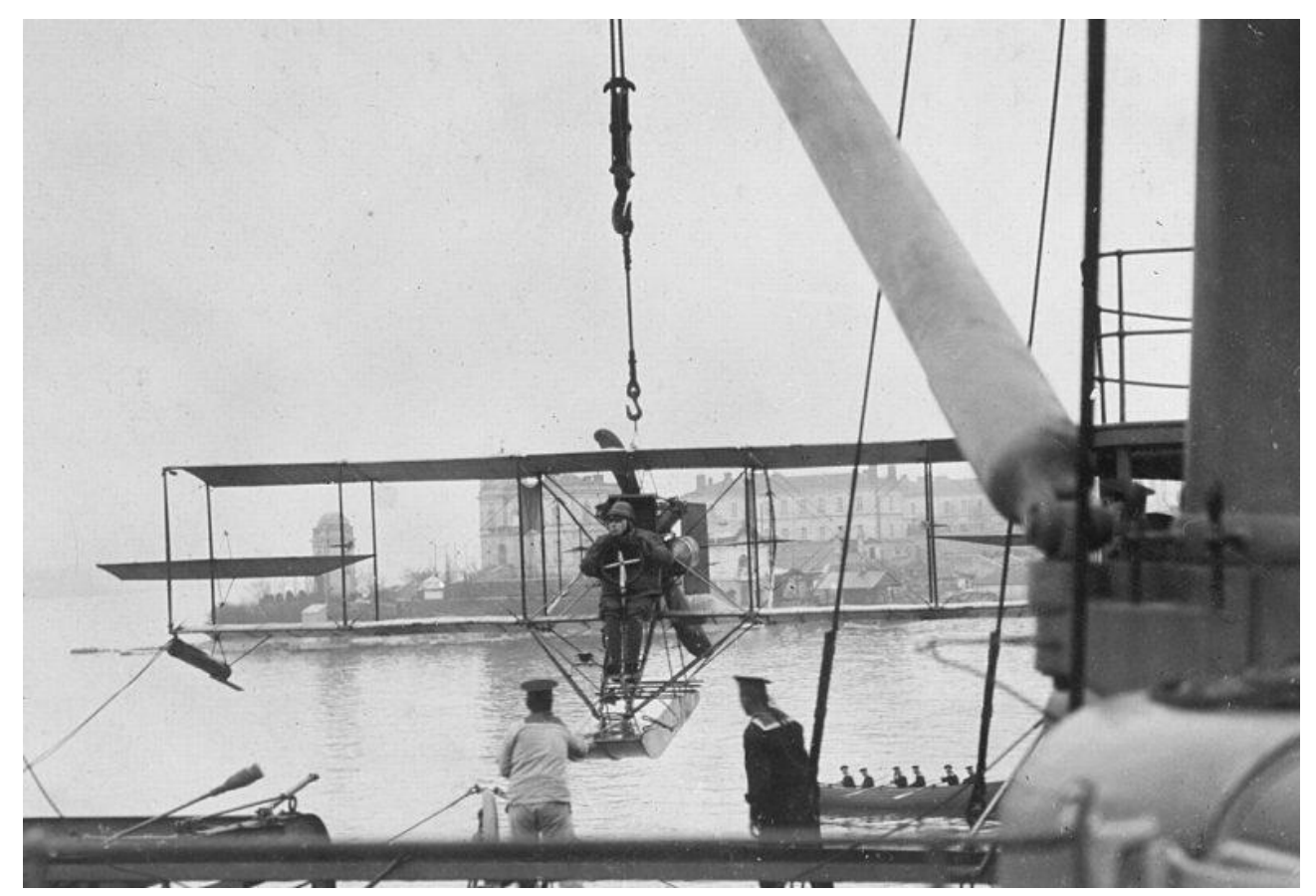

Фото 3 и 4. Подъем аэроплана Кертиса на палубу крейсера "Кагул", январь 1914 г.

В это время русские начали опыты с авиацией на море. 5 января 1913 г. морской министр И.К. Григорович одобрил идею оборудовать на каком-нибудь судне устройства для хранения, спуска и подъема с воды самолета. Потребовалось некоторое время, чтобы выбрать подходящих размеров судно и провести на нем подготовительные работы - в итоге комиссия остановилась на транспорте «Днепр». Пароход имел вместительные грузовые помещения и мощные краны, то есть его можно было переоборудовать в короткие сроки. К середине августа 1913 г. на борт погрузили в разобранном состоянии изготовленный в Килен-бухте по чертежам морских летчиков деревянный ангар. Всего по проекту транспорт должен был принимать 3 аэроплана «Кертис».

26 августа летчики прибыли на корабль и с ними на борт был поднят «Кертис» с бортовым № 6. Сразу же экипаж начал возведение ангара и через 30 минут сооружение имело законченный вид. По окончании подготовки «Днепр» вышел в море и, отойдя на 15 миль от бухты, подготовился к опытам. На следующее утро ангар разобрали и в 14.00 27 августа самолет с пилотом А.Е.Жуковым за 15 минут спустили на воду. Однако взлет осуществить не удалось - морская вода залила двигатель. Самолет подняли обратно и, хотя при этом повредили один из элеронов, повреждение быстро устранили, двигатель прочистили и «Кертис» вновь спустили на воду. Теперь в качестве летчика выступал мичман Н.А. Рагозин, но и ему не удалось взлететь - в результате самолет подняли на борт и транспорт вернулся в порт. Неудача обескуражила командование и, хотя летчики настаивали на продолжении испытаний, их не последовало. штаб:

Весной 1914 г. начальник штаба Черноморского флота писал в Морской Генеральный

«По приспособлению для подъема с воды, хранения на палубе и спуска сделано:

1. Выстроен деревянный разборный ангар.

2. Произведены испытания по сборке и разборке ангара, а также по подъему и спуску с транспорта гидроаэропланов».

В начале Первой мировой войны все оборудование было демонтировано, и пароход использовался как угольный транспорт минной бригады Черноморского флота. Он получил вооружение 1 75-мм и 2 37-мм пушки.

16 декабря 1917 г. перешел на сторону советской власти. В начале июля 1918 г. захвачен в Сухуми немцами и уведен в Севастополь. 24 ноября 1918 г. сдан англо-французским 
войскам. К началу апреля 1919 г. отдан под контроль белых. Уведен сначала в Новороссийск, потом включен как транспорт в состав Морских сил Юга России.

С июля 1919 г. находился в Севастополе. Осенью 1920 г. с беженцами ушел в Босфор, где попал под французский контроль. В 1922 г. продан итальянской фирме «Soc. Marittima Coloniale», Tripoli, Libya (номер по регистру 8) и переименован в «Misurata». С 1923 г. в итальянской фирме "Domenico Saglimbene di Giovanni», Tripoli (Catania).

В 1928 г. пароход купил Felipe Fernandez Aguado из Сантандера и переименовал в «Pilar». Пароход в основном использовался для перевозок по Средиземному морю. В 1931 г. сдан на слом в Бильбао. К сожалению, других подробностей службы бывшего русского авианосца под испанским флагом не известно.

\section{Заключение}

Завершая, хочется отметить, что, несмотря на то, что первые опыты не увенчались успехом, именно эти эксперименты послужили заделом для дальнейших опытов в деле создания авианесущих кораблей.

\section{Примечания:}

1. Герасимов В.Л. Авианесущие корабли русского военного флота // Военноисторический журнал. 2004. № 2. С. 25.

2. Маланина О.В. Авианесущие корабли Черноморского флота в годы Первой мировой войны: опыт применения // Былые годы. 2008. № 2. С. 16-17.

3. Корабли Российского Императорского флота 1892-1917 гг.: энциклопедия / под общ. ред. А.Е. Тараса. Минск, 2000. С. 5 .

4. Бураков. Авиационные корабли, как базы авиации в морской войне // Военный сборник. 1923. № 4. С. 312-317.

5. Герасимов В.Л. Отечественная морская авиация на Черном море в начале XX века // Военная мысль. 2006. № 5. С. 69-76.

6. Пучков А.Г. Морская авиация на Черном море (1910 г. - март 1915 г.) // Вестник архивиста. 2006. № 2-3. С. 442-443.

7. Изонов В.В. О морской авиации в Черном море в начале XX века // Военноисторический журнал. 2006. № 1. С. 76-77.

\section{References:}

1. Gerasimov V.L. Avianesushchie korabli russkogo voennogo flota // Voenno-istoricheskii zhurnal. 2004. № 2. S. 25.

2. Malanina O.V. Avianesushchie korabli Chernomorskogo flota $\mathrm{v}$ gody Pervoi mirovoi voiny: opyt primeneniya // Bylye gody. 2008. № 2. S. 16-17.

3. Korabli Rossiiskogo Imperatorskogo flota 1892-1917 gg.: entsiklopediya / pod obshch. red. A.E. Tarasa. Minsk, 2000. S. 5.

4. Burakov. Aviatsionnye korabli, kak bazy aviatsii v morskoi voine // Voennyi sbornik. 1923. № 4. S. 312-317.

5. Gerasimov V.L. Otechestvennaya morskaya aviatsiya na Chernom more $\mathrm{v}$ nachale XX veka // Voennaya mysl'. 2006. № 5. S. 69-76.

6. Puchkov A.G. Morskaya aviatsiya na Chernom more (1910 g. - mart 1915 g.) // Vestnik arkhivista. 2006. № 2-3. S. 442-443.

7. Izonov V.V. O morskoi aviatsii $\mathrm{v}$ Chernom more $\mathrm{v}$ nachale $\mathrm{XX}$ veka // Voennoistoricheskii zhurnal. 2006. № 1. S. 76-77. 
УДК 94(47).083

\title{
Пароход "Матильда" - к истории первых экспериментов с морской авиацией в России
}

\author{
${ }^{1}$ Роман Витальевич Лапшин \\ ${ }^{2}$ Николай Витальевич Митюков \\ 3 Вячеслав Иванович Меньковский
}

1-2 Международный сетевой центр фундаментальных и прикладных исследований, Российская Федерация

3 Белорусский государственный университет, Беларусь

Доктор исторических наук, профессор

Аннотация. В работе рассматривается история парохода "Матильда" - первого в России судна, способного нести самолеты. Хотя результаты экспериментов не стали выдающимися, они послужили отправной точкой для дальнейших опытов с авиацией на Черноморском флоте.

Ключевые слова: Россия; морская авиация; гидросамолет; пароход. 